\title{
CULTURA MIDIÁTICA E EDUCAÇÃO INFANTIL
}

\author{
Alberto da Silva Moreira*
}

\begin{abstract}
RE SU M 0 : Neste artigo retomo uma discussão já em curso sobre cultura midiática e educação infantil. A partir do impacto social dos conglomerados de comunicação e entretenimento, proponho o conceito de sistema midiático-cultural para dar conta da complexidade crescente no campo da indústria cultural. Para isso examino dois eixos temáticos interligados: 1) a midiatização da cultura e a produção da cultura midiática; e 2) a função socializadora e pedagógica do sistema midiático-cultural nas sociedades modernas, com um acento sobre a publicidade.
\end{abstract}

Palavras-chave: Mídia. Educação. Cultura midiática. Infância. Indústria cultural.

\section{MEDIATIC CULTURE AND CHIIDREN EDUCATION}

A BSTRA CT: This article sums up an ongoing debate on mediatic culture and children education. Based on the social impact of the huge communication and entertainement corporations, it proposes the concept of a mediatic culture system to account for the growing complexity of the culture industry field. It thus analyzes two interconnected subjects: 1 ) the mediatization of culture and the mediatic culture production, and 2) the socializing and pedagogical function of the mediatic culture system in modern societies, focusing especially on advertising.

Key words: Media. Education. Mediatic culture. Childhood. Culture industry.

* Doutor em Teologia, professor-pesquisador da Faculdade de Filosofia e Teologia da Universidade Católica de Goiás (G oiânia) e pesquisador do Instituto Franciscano de Antropologia (Curitiba). E-mail: alberto-moreira@uol.com.br 


\section{A midiatização da cultura - a produção da cultura midiática}

\subsection{0 s conglomerados de comunicação e entretenimento}

surgimento e o desenvolvimento dos meios de comunicação podem ser considerados uma característica essencial da cultura ocidental e uma dimensão marcante da sociedade atual: "Se quisermos entender a natureza da modernidade, (...) as características institucionais das sociedades modernas e as condições de vida criadas por elas - devemos dar um lugar central aos meios de comunicação e seu impacto" (Thompson, 1998, p. 12; 1995, p. 7). Também em sociedades como a brasileira, onde vige uma "modernidade periférica", a produção e a circulação de formas simbólicas pela mídia têm um papel decisivo na vida social e no cotidiano das pessoas.

O emprego sistemático de computadores em praticamente todos os sistemas de comunicação e informação fez aumentar enormemente a velocidade e a qualidade em todas as fases do processo, além de permitir redução de custo e aumento de lucros para as empresas. A revolução digital na transmissão de dados e informações forneceu 0 substrato material para o advento do que Manuel Castells chamou de a sociedade de fluxos (Castells, 1996) ou a sociedade da informação (Castells, 1997 e 1998).

Pode-se objetar a Castells que a maior parte da humanidade ainda não está conectada com essa rede de flux os, que dois terços dela sequer fazem uso do telefone e continuam social e economicamente excluídos. Mesmo assim, não resta dúvida de que os processos de mundialização financeira, econômica, cultural e política vigentes só foram possíveis por meio do desenvolvimento das infotelecomunicações e de seus aparatos. São eles que fornecem o substrato material para o processo de globalização cultural.

O ra, se a globalização for entendida como "produção, distribuição e consumo de bens e serviços, organizados a partir de uma estratégia mundial e voltada para 0 mercado mundial" (O rtiz, 1994, p. 16), ela nada mais é que a expansão dinâmica da economia de mercado (tendência sempre inerente ao capitalismo) a todos os âmbitos da vida social, em todos os países e regiões do mundo, ainda que de forma e em ritmos diferenciados. A globalização econômica, política e cultural serve, segundo Bolaño (1996, p. 17), ao processo de acumu- 
lação e concentração em escala planetária do capital. Assim, podemos dizer que o domínio da informação e das tecnologias da informação "tornou-se fonte alimentadora das engrenagens indispensáveis à hegemonia do capital" (Moraes, 1998, p. 50). Com isso ocorrem:

a) uma internacionalização do mercado cultural de massa com a quebra das barreiras nacionais;

b) a emergência daquilo que 0 rtiz (1994, p. 111) chamou de "cultura internacional popular", ou seja, a formação em cada país de uma massa popular consumidora, sensível a determinadas mensagens, estilos e padrões "globais";

c) uma forte concentração e fusão de empresas e capitais atuantes no campo da indústria cultural em termos mundiais, os oligopólios midiáticos (Herman \& McChesney, 1997; Moraes, 1998, p. 59).

Assim, ao que tudo indica, nos próximos anos - incorporando e remodelando a produção-difusão cultural regional - deverá sobressair a atuação de alguns megassistemas transnacionais de informação e entretenimento altamente concentrados. Segundo a consultoria norte-americana McKinsey, a competição mundial tende a envolver apenas cinco grandes empresas por setor (Moraes, 1998, p. 60). São esses oligopólios midiáticos que produzem, distribuem e organizam, em escala global, a maior parte da informação e das atividades culturais como música, cinema, filmes, shows, livros, revistas, bem como entretenimento, esporte, jogos, lazer, o mercado das artes e a indústria da fantasia infantil e juvenil. (Herman \& McChesney, 1997; Curran \& Gurevitch, 1997). Em todas essas modalidades de atividade cultural as grandes corporações marcam sua presença em nosso cotidiano por meio dos produtos culturais e informativos que produzem, distribuem ou reformatam para uso local. Mesmo não conhecidas do público, muitas empresas estão presentes pelo fornecimento de equipamentos e satélites, ou pelas inúmeras fusões, joint ventures e participações acionárias nas empresas nacionais ou regionais. As dez gigantes globais do setor são: Time-Warner, Disney, Bertelsmann, Viacom e News Corporation, Sony, TCI, Universal, Polygram e NBC. As cinco maiores faturaram US\$ 90 bilhões em 1997; as quatro maiores triplicaram de tamanho nos últimos dez anos e a quinta duplicou; das dez, só três não têm sede nos Estados Unidos: a alemã Bertelsmann, a anglo-holandesa Polygram e a japonesa Sony: "A indústria da co- 
municação pertence aos setores mais dinâmicos do capitalismo global, sob efetiva hegemonia dos EUA como pólo de produção e distribuição de conteúdos" (Herman \& McChesney, 1997, p. 69, 70). ${ }^{1}$

Os "novos missionários do capitalismo corporativo", na expressão crítica de Herman \& McChesney, perseguem uma estratégia global semelhante:

a) ofensividade máxima na guerra industrial e mercadológica em qualquer hemisfério; b) centralização decisória e tecnoprodutiva, conglomeração setorial e desterritorialização das unidades de consumo; c) dispersão transcontinental dos negócios (... ); d) investimentos maciços em tecnologias digitais que estimulem a convergência (... ); e) acordos e joint ventures (...) inclusive com grupos regionais de mídia, visando à otimização comercial de programações, bens e serviços. (Moraes, 1998, p. 72)

No Brasil, outras grandes empresas estrangeiras da área de telecomunicações e computação já atuam no mercado: Telefônica, AT\&T, Microsoft, IBM, Compaq, AOL, Lucent, Siemens. Os grupos nacionais mais fortes - Organizações G lobo, Grupo Abril, Grupo Silvio Santos, Grupo Folha, Estado e Igreja Universal - transmitem e distribuem programas e conteúdos dos grandes conglomerados ou possuem projetos em colaboração com eles.

Em 2002 foi aprovado no Congresso um projeto de lei que abre às multinacionais a participação na composição acionária de empresas brasileiras do setor das comunicações. A pressão dos oligopólios midiáticos, de governos e órgãos financiadores internacionais, aliados a interesses de grupos locais, deve conduzir a um grau ainda maior de desnacionalização da cultura (midiática) produzida e difundida no Brasil. Todos esses trâmites ocorreram praticamente sem informação e participação do público brasileiro.

\subsection{A midiatização da cultura}

Qual é o impacto social que esse conjunto de mudanças contido na expressão "globalização cultural" provoca nas culturas locais? 0 que ocorre no repertório cultural de relatos, identidades, símbolos, lendas e memórias dos grupos sociais e dos povos a partir da interação com o mercado de bens simbólicos transnacionais, onde dominam os grandes conglomerados da cultura e seus sofisticados meios técnicos? 
Em razão da magnitude e da complexidade dos processos, não existe, é claro, uma resposta simples a essas perguntas. Aumentam por isso o interesse e os estudos sobre o que ocorre no campo da cultura (Featherstone, 1994 e 1995) e do imaginário local (religiões, valores, idéias e tradições) com a expansão global de estilos de comportamento, consumo e pensamento, de gostos e preferências, e da popularização de fragmentos desconexos das culturas locais. Talvez a característica mais marcante da globalização cultural seja o fato de ela acompanhar e contribuir para o estabelecimento e o funcionamento da economia de mercado em escala planetária. O utra característica, já apontada acima, é o surgimento de uma cultura internacional de massa, ao lado ou por dentro das culturas locais.

A própria dificuldade sentida de circunscrever o conceito de cultura já é indicadora da segmentação (pós)moderna de um pensamento que parece ter abdicado de qualquer recurso à totalidade (G eyer, 1994). Se inicialmente e para efeitos operativos tomarmos cultura, na linha de Berger \& Luckmann (1978), como "construção social da realidade", o que implica a criação, reprodução e difusão de sistemas de atitudes e modos de agir, de costumes e instituições, valores espirituais e materiais, devemos admitir que justamente neste âmbito se constituiu um grande e complexo mercado de "bens" simbólicos ou "textos" culturais. Hoje, mais que nunca na história, os agentes privilegiados no processo de (re)criação e difusão de valores, comportamentos, gostos, idéias, personagens virtuais e ficção são as grandes empresas transnacionais da mídia, da publicidade e do entretenimento (Adorno, 1970; Adorno \& Horkheimer, 1982; Giraud, 1989; Mattelart, 1986 e 1994; Chomsky \& Herman, 1988 e 1997). Essas corporações, cujas empresas conjugam televisão, computadores, Internet, vídeo, cinema, aparelhos de diversão eletrônicos, mas também rádios, revistas, jornais, outdoors, banners e outras formas de comunicação imagética, sonora e/ ou virtual, são agentes sociais poderosos. Elas, mais pelas características de sua atuação social que por sua organização interna ou setorial, parecem estar constituindo um verdadeiro sistema midiático-cultural.

A presença ubíqua desse sistema midiático-cultural, a sua ação pervasiva e constante e o poder simbólico de que dispõe estão provocando modificações profundas no âmbito da cultura, em todos os seus aspectos. Talvez a mais importante dessas transformações seja 0 fato de que a própria cultura é cada vez mais midiatizada. 
Por midiaçã $0^{2}$ da cultura entende Thompson (1995, p. 21) o processo histórico do rápido crescimento e da proliferação de instituições e meios de comunicação de massa nas sociedades ocidentais, que, por intermédio de suas redes de transmissão, tornaram formas simbólicas mercantilizadas acessíveis a um grupo cada vez maior de receptores. Em outros termos, a produção e a transmissão das formas simbólicas (que refletem as experiências e as visões de mundo das pessoas) são sempre mais mediadas pelas instituições e pelos aparatos técnicos da mídia. A cultura "passa" ou "acontece" cada vez mais na e por meio da mídia. Isso implica: a) que as manifestações culturais mais diversas só são reconhecidas como tais pela sociedade depois de serem "mostradas" ou incorporadas pela mídia; b) que as próprias criações, os personagens e produtos da mídia se tornam bens culturais de alcance social. Ambos os níveis interagem, de forma que a mídia se torna ao mesmo tempo acontecimento, produção e divulgação cultural. Tal abrangência justifica a introdução do conceito de sistema midiático-cultural. Um dos resultados desse processo é a produção da cultura midiática.

\subsection{0 que se entende por cultura midiática}

Cultura midiática tem a ver com determinada visão de mundo, com valores e comportamentos, com a absorção de padrões de gosto e de consumo, com a internalização de "imagens de felicidade" e promessas de realização para o ser humano, produzidas e disseminadas no capitalismo avançado por intermédio dos conglomerados empresariais da comunicação e do entretenimento, e principalmente por meio da publicidade. Num âmbito mais amplo e necessariamente genérico, cultura midiática é a cultura do mercado pensada e produzida para ser transmitida e consumida segundo a gramática, a lógica própria, a estética e a forma de incidência e recepção peculiares ao sistema midiáticocultural. Neste sentido, a noção de cultura midiática é devedora e retoma muitas implicações do conceito de indústria da cultura, ou indústria cultural, mas deseja apontar ou circunscrever realidades específicas do estágio atual de midiatização da cultura. ${ }^{3}$

Cultura midiática é o produto regular e sempre renovado de um sistema midiático-cultural, cujos principais agentes - os conglomerados midiáticos - colocam a sofisticação tecnológica a serviço da reprodução do mesmo, da "banalidade sintética, fabricada em circuito 
fechado e sob tela de controle" (Baudrillard, 2001). Na cultura midiática não se trata apenas da conformação do público a determinados hábitos, padrões de comportamento, valores, gostos e preferências, difundidos por meio da mídia, mas da criação, duplicação ou da recriação da realidade por meio dela. Em alguns dos seus produtos, como os reality shows (do tipo Big Brother, Casa dos A rtistas, Ilha da Sedução) que tudo pretendem mostrar (ou seja, a realidade), essa cultura midiática vai além da própria realidade: virtualiza um real degradado à mais rasa banalidade para o consumo narcisista de um público que dá à simulação (ao vivo) de sua própria cotidianidade, tornada insignificante pelo excesso de exposição e pela orgia imagética, sua mais entusiástica adesão (Zamora, 2000, p. 34).

Ao assumir o conceito de cultura midiática nesta acepção críti$\mathrm{ca}$, tenho em mente alguns fatores delimitadores que, a meu ver, não negam, mas recortam e contextualizam, essas afirmações:

a) Não se trata de fazer uma mistura indiscriminada de todas as formas e produtos mass-midiáticos, como se todos agissem da mesma forma, seguissem os mesmos objetivos e alcançassem resultados semelhantes.

b) Existem diferenças de forma e conteúdo mesmo entre peças de publicidade: a propaganda de um governo autoritário não tem o mérito ético-político de uma campanha da Anistia Internacional; um comercial da Coca-Cola não tem a relevância social de um anúncio sobre os perigos da AIDS, ainda que na sua confecção ambos possam utilizar recursos similares de comunicação e marketing.

c) Não se quer afirmar que a influência das indústrias culturais seja sempre negativa; em algumas situações é justamente 0 contacto com mensagens e horizontes culturais mais amplos que 0 autoritarismo de determinadas tradições locais que enriquece e anima movimentos e lutas por democracia e direitos humanos. ${ }^{4}$

d)Em circunstâncias específicas (luta ecológica, reivindicações globais, movimentos populares transnacionais) a mídia tanto pode dissimular como disseminar atitudes e sentimentos de inconformismo, quando não de revolta popular. Este parece ser 0 caso das recentes coberturas sobre eventos como 
Seattle, Davos e o Fórum Social de Porto Alegre: o movimento popular tanto pode ser ajudado como difamado pela mídia.

e) Não é possível prever e controlar totalmente o processo de recepção, leitura e reação por parte do público; mesmo campanhas publicitárias milionárias podem tornar-se grandes fracassos financeiros, e ações cuidadosamente planejadas podem provocar efeitos inesperados e indesejados.

Está claro que a midiatização da cultura, por intermédio do papel preponderante dos conglomerados da comunicação, informação e entretenimento, acirrou a crise das instituições tradicionais produtoras de sentido (escola, família, religiões, Estado, culturas locais) e facilitou a constituição de novas instâncias geradoras e difusoras de sentido (Moreira \& Zicman, 1994). Esse processo, que é fundamental para se entender as sociedades modernas, ocorre de forma não-linear ou programada e está cheio de conflitos, resistências, releituras e reações. Também não se deve pensar, como sublinha Thompson (1998, p. 13), que os meios de comunicação falem a indivíduos e sociedades estáticos, a entidades fechadas e "indefesas" que deveriam ser, portanto, "protegidas" da má influência "externa". Toda cultura se forma e reforma constantemente no contacto com o diferente e 0 exterior a si mesma. A própria noção do que é o "diferente" e do que é o "exterior", de quem somos "nós" e de quem são "eles", precisa ser continuamente refeita e reposta. Assim, a identidade é construída num processo social e simbólico, historicamente específico a cada grupo ou povo. Conforme Woodward (2000, p. 14), "A identidade é, na verdade, relacional, e a diferença é estabelecida por uma marcação simbólica relativamente a outras identidades (...) [ela] está vinculada também a condições sociais e materiais".

Envolvidos nesse processo social e simbólico de contínua construção e re-posição da identidade,

é por meio dos significados produzidos pelas representações que damos sentido à nossa experiência e àquilo que somos (...). A representação, compreendida como um processo cultural, estabelece identidades individuais e coletivas e os sistemas simbólicos nos quais ela se baseia fornecem possíveis respostas às questões: Q uem sou eu? O que eu poderia ser? Q uem eu quero ser? (Idem, ibid., p. 17) 
A partir dos discursos e das visões de mundo produzidos pelos sistemas de representação simbólica, os sujeitos podem se posicionar e construir sua identificacão com determinados papéis, perfis, significados. Baseados nessa identificação subjetiva, na qual sempre estão presentes desejos e dinâmicas do inconsciente, os sujeitos afirmam ou não seu pertencimento: isso somos nós (e não aquilo), fazemos parte dessa cultura/ povo/ comunidade (e não daquela outra).

Percebemos logo que, em todos os momentos do processo social-simbólico de construção e afirmação da identidade e do pertencimento, a atuação do sistema midiático-cultural é marcante. 0 sistema midiático tornou-se nas sociedades modernas talvez o principal fator gerador e difusor de símbolos e sentidos. Símbolos e sentidos estes que geram tanto sentimentos de identificação e de pertencimento como de anomia e exclusão. Anúncios publicitários só são eficazes porque têm apelo para os consumidores, porque fornecem imagens com as quais eles podem se identificar. A presença da mídia é decisiva porque suas histórias, mensagens e anúncios, como de resto todas as práticas de significação que produzem significados, "envolvem relações de poder, incluindo o poder para definir quem é incluído e quem é excluído". ${ }^{5}$

Isso nos lembra que as representações simbólicas, incluindo as identidades, estão no entrecruzamento das nossas vidas cotidianas com as relações sociais, econômicas e políticas e não podem ser dissociadas delas. ${ }^{6}$ Assim, uma análise que se restringisse a examinar a linguagem ou o conteúdo de um produto midiático como algo "em si e para si", dissociado dessa ubicação nas relações sociais mais amplas, falharia com seu próprio objeto de estudo.

Em contrapartida, a própria atuação dos meios de comunicação de massa fez surgir novas formas de ação e interação social, novas formas de relacionamento do indivíduo consigo mesmo e com os outros. Ao influenciar o processo de construção das identidades, ao estimular determinadas lealdades e pertencimentos e ao favorecer determinada visão de mundo, o complexo midiático-cultural tornou-se talvez, o principal agente no processo cultural. Essa é uma mudança significativa.

Em algumas situações os produtos da mídia podem ter oxigenado as tradições: ao transplantá-las para outros contextos, ao relativizar formas tradicionais e autoritárias de vida e ao oferecer às 
pessoas novas fontes de identidade desconectadas de seus locais particulares (Thompson, 1998, p. 15). Talvez a contribuição mais significativa das redes de informação tenha sido seu papel no processo de formação de uma consciência planetária. Nossa imagem do mundo de fato se transformou. Sabemos que não podemos mais pensar em termos simplesmente locais e isolados; percebemos a realidade de povos e situações antes distantes no tempo e no espaço, e de como estamos interligados. Surgiu uma realidade nova na história humana: a constituição (real) de uma sociedade-mundo, e uma percepção (ideal) do planeta Terra como casa dos humanos e de toda a biosfera. Sem dúvida a atuação dos meios de comunicação de massa foi fundamental neste processo, rompendo a barreira dos Estados, das línguas e das culturas regionais.

Dessa forma, não pretendo fazer juízos totalizantes ou definitivos sobre a atuação da mídia. Para ajuizar devidamente as situações são sumamente importantes os trabalhos sobre formas simbólicas específicas e estudos de caso sobre a recepção e a incidência dos produtos midiáticos. Acerca dessas questões debateu-se mais de meio século nas ciências sociais e na comunicação, desde Lazarsfeld passando por Adorno e Horkheimer, Marcuse e McLuhan até Niklas Luhmann, Baudrillard, Paul Virilio, Néstor G arcia Canclini, Jesús MartínBarbero e Muniz Sodré, só para citar alguns nomes.

Inegável, contudo, parece-me o fato de que o sistema midiáticocultural elabora e difunde, mesmo se de uma forma não totalmente intencional ou planejada, visões de mundo, sentidos e ex plicações para a vida e a prática das pessoas e, por isso, passa a influenciar sempre mais seu cotidiano, sua linguagem e suas crenças. Justamente 0 âmbito das crenças e da elaboração do sentido, da visão de mundo como uma atitude fundamental perante 0 real, que tradicionalmente foi um espaço ou uma função atribuídos à família, à escola, às religiões e filosofias, está hoje, em boa parte, concentrado nas mãos dos agentes midiáticos.

Ao garantir internamente a existência da contradição e da ruptura, da possibilidade de reapropriação da mídia pelos movimentos sociais, da existência dos ruídos e das ressignificações realizadas pelo público, enfim: do caráter não monolítico ou total do sistema midiático-cultural, não pretendo obliterar a sua orientação de fundo e sua pragmática busca das duas forças decisivas na sociedade capita- 
lista: 0 lucro e o poder. Não se pode desconhecer o fato de que qualquer mensagem e produto veiculados pela mídia vêm marcados por características básicas:

- Na mídia nunca temos a ver com a realidade, mas com a sua imagem, relato ou reduplicação tecnológica; trata-se sempre de "experiências de segunda mão" (Arnold Gehlen).

- Todos os "eventos", fatos e processos relatados, mesmo as maiores tragédias, reclamam uma audiência, que deve ser constituída e alimentada.

- A mídia depende essencialmente da publicidade, da propaganda e do marketing como fonte de financiamento.

- Notícias, filmes, programas, músicas são produzidos como mercadorias para serem vendidas e, portanto, precisam gerar lucro.

- Nesse processo as mensagens e informações são transformadas exteriormente e às vezes internamente.

- Elas são produzidas e disseminadas por poucos e grandes conglomerados, ou seja: supõem uma enorme concentração do poder simbólico (e econômico e político) em poucas mãos; produções alternativas e de cunho crítico existem, mas têm grande dificuldade de atingir o grande público.

- Os veículos da mídia funcionam praticamente em uma única direção - raramente permitem intervenção, modificação ou diálogo de fato; as formas de interatividade existentes não questionam fundamentalmente 0 esquema, mas antes 0 reforçam.

- Mensagens e produtos são quase sempre formatados com 0 intuito de criar uma mentalidade afirmativa (Adorno), uma adesão subjetiva ao real existente; seu interesse não é alimentar visões radicalmente distintas das do establishment.

Resumindo: Em que sentido, então, pode-se entender a midiatização da cultura, a constituição de um sistema midiático-cultural e o surgimento de uma cultura midiática?

1) Primeiro, no sentido de que em nossas sociedades tendencialmente todas as expressões culturais, como a arte, as manifestações populares, a literatura, a política, a religião 
etc., passam ou acontecem por meio da mediação desse sistema de transmissão simbólica; ele é pervasivo.

2) Segundo, no sentido de que o próprio sistema midiático-cultural produz padronizações, fórmulas, esquemas, formatações e expectativas que retroagem e influenciam as manifestações culturais, gerando um processo de mútua influência.

3) Terceiro, no sentido de que o sistema midiático gera e difunde uma cultura que, se não lhe é própria (pois a "matéria-prima" para o seu "produto" em geral não é criada por ele, mas retirada ou "vampirizada" de outros repertórios de significantes, como a cultura popular), pelo menos lhe é adequada: a cultura midiática reorganiza a percepção do espaço e do tempo (Sandbothe \& Zimmerli, 1994), difunde poderosamente no imaginário e na prática social das pessoas seus próprios ritmos, espacialidades, formas de interação social, noções de identidade e de pertencimento.

4) Q uarto, no sentido de que seus símbolos, ícones, imagens, valores e mensagens, produzidos por poucos, com nenhuma ou pouquíssima intervenção dos receptores, são revestidos de um poder ou potencial simbólico enorme; tal poder simbólico pode ser considerado ideologia se e enquanto tais produtos contribuem para criar ou reforçar formas de dominação explícita ou camuflada (Thompson, 1995).

5) Q uinto, no sentido de que o sistema midiático-cultural exerce uma evidente função socializadora e "educadora" da sociedade, sobretudo dos segmentos mais expostos a ele, como as crianças; isso independe, em princípio, se os conteúdos veiculados são negativos ou positivos.

6) Sexto, no sentido de que sua ação é sutil e atua sobre 0 inconsciente, e por isso não pode ser captada quantitativamente; a mídia influencia muito mais pela sedução que pela argumentação.

7) Sétimo, no sentido de que, por ser pervasivo, comprometido ideologicamente e atuar sobre o inconsciente, o sistema midiático-cultural influencia poderosamente na própria percepção que os sujeitos têm da realidade. 
8) O itavo, no sentido de que as instituições de produção e transmissão simbólica atuam como empresas, que produzem, reprocessam, armazenam, vendem e distribuem mercadorias (bens simbólicos) num mercado; ou seja: trata-se de instituições que se orientam pela busca do lucro (e do poder que ele viabiliza) e não necessariamente por valores humanos ou democráticos.

\section{A função socializadora e pedagógica do sistema midiático-cultu- ral nas sociedades modernas}

\subsection{C rise das instâncias produtoras de sentido}

Conforme explicitado acima, o sistema midiático-cultural acirrou a crise de outras instâncias produtoras de explicação e sentido para a vida social. Tradicionalmente a família, a escola, a religião e 0 Estado eram os responsáveis pela produção e divulgação das formas simbólicas. Eles tinham tempo e meios para impregnar as novas gerações na fidelidade aos "sentidos" gerados. 0 que nem sempre contribuiu para aumentar o espaço de liberdade e expressão dos indivíduos. Em todo caso, tal situação mudou bastante com 0 advento dos conglomerados midiáticos.

Para dar um exemplo, o papel do E stado como criador e administrador das políticas públicas para a área da comunicação se enfraqueceu bastante no processo de globalização. Com a diminuição da autonomia dos Estados nacionais, pelo menos daqueles mais fracos, os conglomerados internacionais de comunicação e entretenimento impõem ao mercado mundial seus produtos midiático-culturais (filmes, notícias, jogos, imagens, sons, música etc.). Eles exigem para seus produtos as mesmas regras do livre "mercado" e da "livre difusão" como qualquer outra mercadoria; ou seja, os países não podem pôr entraves à sua circulação (G iraud, 1989, p. 273).

D essa forma, a maioria dos países, sobretudo aqueles pobres que não têm uma legislação específica para o setor, ou cuja produção midiática é inexistente ou insignificante, é invadida pela enxurrada de mercadorias culturais produzidas por algumas grandes empresas transnacionais. No mundo árabe, por exemplo, a agressiva política de divulgação dos enlatados ocidentais, inclusive filmes e publicações 
pornográficas, têm provocado reações iradas e alimentado o fundamentalismo islâmico. Alguns autores também têm denunciado a massiva presença do tele-evangelismo norte-americano por sua manifesta imbricação com interesses geopolíticos dos Estados Unidos, inclusive por meio de financiamentos por parte da CIA (Lima, 1987; Assmann, 1990; Carvalho, 1998). Portanto, a expressão imperialismo cultural ainda não pode ser descartada nas discussões sobre 0 assunto.

\subsection{A socialização da infância pela publicidade midiática}

Q uanto ao papel e à influência da escola sobre as crianças e os adolescentes (sem fazer apologia de qualquer "modelo pedagógico"), basta refletir sobre alguns indicadores para se perceber o quanto essa influência está sendo relativizada:

As indústrias culturais transnacionais, orientadas pelo lucro (definidas livremente como setores que usam símbolos, histórias, imagens e informações para gerar ganhos financeiros), são hoje as mais poderosas instituições culturais do mundo - contando mais histórias, cantando mais canções, provendo mais imagens e combinando mais metáforas que qualquer outro grupo de instituições do mundo (...). As indústrias culturais hoje dominam a vida nas regiões industriais avançadas e sua influência continua a se espalhar. Nos Estados Unidos seus produtos eatividades ocupam mais do tempo das pessoas do que qualquer outra coisa, exceto o trabalho, a escola e o sono (...). (Budde, 2001, p. 66)

Parece-me inequívoco que os diversos meios de comunicação exercem hoje uma função pedagógica básica, a de socializar os indivíduos e de transmitir-lhes os códigos de funcionamento do mundo. Sem dúvida instituições como a família, a escola e a religião continuam sendo, em graus variados, as fontes primárias da educação e da formação moral das crianças. Mas a influência da mídia está presente também por meio delas. A televisão, por exemplo, ocupa uma fatia considerável do tempo das crianças, sobretudo em meios sociais carentes de fontes alternativas de ocupação e lazer:

Considere que pela primeira vez na história humana as crianças nascem em casas nas quais a televisão fica ligada uma média de 7 horas por dia. E que pela primeira vez a maioria das histórias não é contada pelos pais, nem pela escola, nem pela igreja, nem pela tribo ou comunidade e, em muitos lugares, nem mesmo pelo país de origem, mas por um grupo relativamente pequeno de conglomerados empresariais que possuem algo para vender. (Gerbner, 1998, p. 2, apud Almeida Jr., 2001, p. 50) 
Mas, ao falar sobre a função socializadora da mídia, devemos dar atenção especial a um setor emblemático de sua atuação, a propaganda. A propaganda atualmente é o principal vetor do sistema midiático-cultural e talvez traduza emblematicamente a "essência" mesma desse sistema. Eis algumas razões para essa suposição: em primeiro lugar, a ligação intestina do sistema midiático-cultural com a publicidade é clara: a propaganda é a principal fonte de financiamento dos conglomerados midiáticos. Nos Estados Unidos, por exemplo, a imprensa depende da publicidade em cerca de $3 / 4$ de sua renda; as rádios e televisões dependem totalmente dela e mesmo os canais públicos estão cada vez mais dependentes desta fonte de financiamento (Schiller, 1994, p. 33). Em segundo lugar, como os produtos culturais veiculados pela mídia são, também, mercadorias destinadas ao consumo, eles possuem uma certa co-naturalidade com as peças publicitárias, que visam explicitamente a tal consumo. Em terceiro lugar, o próprio formato, o estilo, a linguagem visual e os recursos das peças publicitárias (por exemplo, do spot) passam a in-formar e conformar outras produções midiáticas, como os shows, o jornalismo e 0 cinema. Busca-se integrar a eficácia comunicativa da publicidade aos demais produtos midiáticos (concisão, impacto, rapidez, evidência, impressão duradoura). Isso sem mencionar os casos mais corriqueiros de propaganda explícita ou velada nas novelas e nos filmes. A indústria da publicidade, por si, é um dos ramos mais cobiçados do sistema midiático-cultural, movimentando um orçamento global de US\$ 400 bilhões em 2002 (Moraes, 2003, p. 205). No Brasil, foram investidos R $\$ 12,9$ bilhões em publicidade em 2000, sendo 63,5\% na televisão. ${ }^{7}$ Para um autor crítico como Herbert Schiller, este conjunto de fatores implicaria no longo prazo a transformação da imprensa, do rádio, da TV a cabo, da Internet e de qualquer tecnologia subseqüente em instrumentos do marketing.

Todavia é preciso avançar na compreensão da propaganda. Como os estudos de Leiss, Kline \& Jhally $(1997$, p. 5) inequivocamente mostraram, a publicidade não constitui simplesmente um setor na estrutura produtiva ou de consumo, ao lado de outros setores, como a agricultura, o vestuário ou a pesca. Ela pervade todos os setores. A propaganda e 0 marketing tornaram-se na verdade um environment, um "ambiente cultural" dentro do qual as pessoas nascem e crescem, como se fosse essa uma "cultura", sua "própria" cultu$\mathrm{ra}, 0$ ar que respiram. Este ambiente cultural sui generis, povoado por 
entidades às quais se agregam qualidades, as marcas, impregnado de relações de compra e venda, cujo interesse maior não é vender produtos, mas formar para o consumo, tornou-se uma presença pervasiva também no universo infantil.

O norte-americano médio é exposto a pelo menos três mil propagandas a cada dia e gastará três anos de sua vida assistindo a comerciais de televisão. As propagandas perfazem cerca de $70 \%$ de nossos jomais e $40 \%$ de nossas correspondências. Naturalmente, não prestamos atenção direta à maioria destas propagandas, mas somos poderosamente influenciados, geralmente em um nível inconsciente, pela experiência de estar imersos em uma cultura da propaganda, uma cultura voltada para o mercado, na qual nossas instituições políticas, religiosas e educacionais estão crescentemente à venda pela oferta mais alta. (Kilbourne, 1999, p. 58-59, apud Almeida Jr., 2001, p. 50-51)

Em alguns países e camadas urbanas, adultos e crianças gastam entre 24 e 30 horas por semana assistindo à televisão, isso sem contar o tempo que passam escutando rádio ou música, lendo jornais e revistas, conectando-se com a Internet ou consumindo outros produtos culturais da mídia (Thompson, 1995, p. 9). Calcula-se que um jovem norte-americano aos 14 anos de idade já viu cerca de 22 mil mortes nos meios de comunicação, e já terá deglutido (passiva ou ativamente) alguns milhões de propagandas (O 'Sullivan, D utton \& Rayner, 1998, p. 4-5).

O corre que a atenção ou audiência do público se tornou uma mercadoria escassa e disputada; os conglomerados midiáticos vendem-na caro aos anunciantes e dela dependem para se manter. Por isso a necessidade de garantir cotas de audiência ou de mercado passa a ser buscada como critério decisivo em todas as fases de produção dos programas e das revistas, também aqueles dirigidos ao público infantil. Essa audiência ou atenção precisa ser explorada ao máximo e assim, além da publicidade explícita, o comercial é misturado ao próprio conteúdo do produto midiático. 0 consumo da marca torna-se parte integrante da própria mensagem: "Os meios interativos anunciam um conjunto inteiramente novo de relações, derrubando as barreiras tradicionais entre o 'conteúdo' e o 'comércio', e criando intimidades sem precedentes entre as crianças e os marqueteiros" (Montgomery, 2000, p. 636).

A publicidade na Internet, na TV e nos jogos eletrônicos - em conseqüência do grau de imersão, envolvimento emocional, prazer e 
criatividade que permitem - está fomentando lealdade a marcas e estilos, criando entre as crianças e os adolescentes "comunidades virtuais" de "amigos" ou de "parceiros" de determinado produto. Cada vez mais cedo o imaginário infantil é cooptado e povoado por marcas e logos, os ícones do consumo. ${ }^{8}$

Não é preciso muita imaginação para se perceber que essa colonização do simbólico pela propaganda vai influenciar a formação cultural e espiritual das crianças. Elas estão sendo acostumadas (como nós adultos) a consumir não apenas aquilo que a publicidade indica, mas a consumir a própria publicidade como modo de ser. Modo de ser como exteriorização e ser-para-fora, ser como narcisismo e publicidade do privado, ego como sucesso mercadológico, raso e banal. O utro não parece ser o sentido do costume recente de pagar milhões por declarações de amor espalhadas pelos outdoors da cidade. Aqui 0 espaço-veículo publicitário se confunde com sua mensagem-produto; a intimidade degradada e banalizada torna-se mercadoria para 0 consumo da multidão. Como o modo de ser da publicidade é necessariamente 0 do efêmero e do descartável, essa tirania da sobreposição nivela e erode, no limite, qualquer valor. No vácuo axiológico que ela ajudou a criar, a propaganda tenta estabelecer seus próprios valores, ritos e crenças. Julgo, portanto, que não há exagero quando a intelligentsia da propaganda e do marketing mundial, numa reportagem do F inancial Times, declara serem as marcas uma religião, talvez a única religião universal dos nossos dias:

"Brands are the new religion", declared Young \& Rubicam, one of the world's biggest advertising agencies, this week as it published its annual league table of global consumer brands. Successful brands, it explained, stood for more than a product. They represented a set of beliefs and the people who built them were like the missionaries who spread Christianity and Islam around the world. "The brands that are succeeding are those with strong beliefs and original ideas", Y \& R said. "They are also the ones that have the passion and energy to change the world and to convert people to their way of thinking though outstanding communications." ${ }^{\prime 9}$

Mais que as religiões e as culturas locais, quem parece agenciar hoje os símbolos de identificação, valores e estilos de ser na aldeia global, são as marcas e os logos, manipulados pelas agências de publicidade e seus "gurus". Esses "novos missionários" (como os antigos) dedicam especial atenção ao público infantil e adolescente, pois sabem 
que as crianças são mais receptivas à sua pregação. Todavia, ao invés do catecismo chato a ser decorado, a nova "catequese" é agradável e envolvente: ela se vale de sons, ritmos, imagens cativantes e muito humor. E começa muito mais cedo, no ventre da mãe. Trata-se, sobretudo, de formar hábitos e lealdades nos pequenos. Sem deveres e castigos, a religião do consumo só promete recompensas. Por isso conta com a adesão entusiasta das crianças, pois a inteligência, a sofisticação e a interatividade embutidas na propaganda fascinam e envolvem pelo prazer que produzem.

Assim, antes de serem alfabetizadas pela escola, as crianças, sobretudo nos grandes centros, já foram alfabetizadas pelas marcas e pelos logos. Antes de aprenderem direito a falar, elas começam a ler 0 mundo por meio dos ícones do consumo. Na verdade, muitas de suas primeiras palavras já vêm desse ambiente. A publicidade e 0 marketing, legitimados e escorados no seu tremendo sucesso econômico, vão mostrando às crianças pela vida afora o que é agradável, atraente, criativo e, sobretudo, desejável. No fundo, o que vale a pena. Qual outra instituição social disputa com eles essa univocidade axiológica ditatorial?

Para isso, as crianças precisam ser submetidas a uma saturação simbólica sem precedentes. Esse excesso de informação e de sentido é veiculado por empresas de bens simbólicos, disputando a atenção e o bolso dos pequenos consumidores. Alguns canais de televisão, por exemplo, dirigem sua programação exclusivamente para crianças de até 5 anos. ${ }^{10}$ Uma característica da saturação simbólica é 0 uso direcionado e planejado das imagens comerciais para o público infantil.

\subsection{Saturação de imagens - preguiça do pensamento}

Ao falar de um excesso ou "orgia imagética", quero apontar para o predomínio da imagem nas formas de apreensão e representação do mundo presentes na cultura midiática. Não se trata aqui de entrar no debate já longo, levado a efeito na semiótica e na lingǘstica, sobre uma possível subordinação ou decadência da palavra (ou da escrita) com relação à imagem (Santaella \& Nöth, 1999, p. 58 e ss.). 0 que me parece importante ressaltar é justamente 0 que a pesquisa na semiótica revelou acerca da eficiência específica da imagem com relação à linguagem: 
D e acordo com esta, as imagens atuam mais fortemente de maneira afetivo-relacional, enquanto a linguagem apresenta mais fortemente efeitos cognitivo-conceituais. (Janney \& Arndt, 1994) Imagens fomentam atenção e motivação, são mais apropriadas à apresentação de informação espacial e facilitam, em certo grau, determinados processos de aprendizagem. (Weidenmann, 1988, p. 135-138) A eficácia emocional das imagens cresce com o grau de sua iconicidade. (Reimund, 1993). (Santaella \& Nöth, 1999 , p. 44)

A eficácia emocional das imagens aumenta com o seu grau de iconicidade, mas em geral não se dispensa o texto ou a fala. 0 filme, 0 anúncio na revista, ou o comercial na televisão, por exemplo, articulam de maneira pensada as duas coisas, para que o texto potencialize a imagem. A técnica pode ser observada tanto num filme de Fellini como num comercial de cerveja, com evidente diferença qualitativa de conteúdo. De todo modo, a exposição de crianças e jovens às imagens, sobretudo publicitárias, é constante e duradoura. Além disso, essa exposição se dá freqüentemente em ambientes que requerem uma total imersão do indivíduo, como na Internet, nos videogames e nos jogos interativos.

A seqüência frenética de imagens, a sensação de desafio e "perigo", os movimentos rápidos e coordenados, concentração total e gratificação instantânea: esse conjunto de fatores leva muitos adolescentes a se tornarem literalmente viciados em Internet e nos jogos eletrônicos. Alguns passam mais de oito horas por dia, semanas inteiras, jogando videogame. ${ }^{11}$ Aparecem sempre mais os casos de morte por "overdose de Internet". ${ }^{12}$ Nesses casos a linguagem e 0 raciocínio argumentativo dos indivíduos tendem a se embotar. Os adolescentes desenvolvem destreza e raciocínio seqüencial rápido, mas perdem o interesse em aprender a pensar. O consumo compulsivo de imagens ultra-rápidas, aliadas a sons exóticos e ritmos extasiantes, pode levá-los a buscar um estado de constante excitação. Em tal situação, é muito mais difícil organizar argumentativamente seus próprios sentimentos, projetos e desejos.

O s jovens aprendem cedo a realizar tarefas de grande complexidade científica e tecnológica, mas parecem existencialmente mais infantis, narcísicos e inseguros. A cultura-vídeo, sobretudo por meio da imersão na realidade virtual, favorece o espelhamento narcísico, mas não fomenta nenhum amor do jovem por si próprio: "A deslocação do interesse libidinal para a própria imagem realiza-se em troca de 
uma completa anulação da vida interior e do próprio eu real" (Perniola, 1994, p. 49, apud Sodré, 2002, p. 156). Adolescentes viciados em Internet podem perder aderência à realidade circunstante, além de involuir na sua capacidade para formar e manter vínculos afetivos diretos. Eles tendem a diminuir seu interesse pelas formas diretas de sociabilidade e a se isolar. A expressão de afetos, desejos e emoções é canalizada para e-mails e chats, ou seja: as crianças e os jovens desenvolvem uma sociabilidade mediada pelos aparatos eletrônicos, numa ausência de vinculações comunitárias. Tal sociabilidade pode ser, em tese, mais ampla, mas será certamente mais superficial e efêmera.

\subsection{Mudanças na percepção da realidade}

Sempre se disse que a mídia influencia na percepção da realidade. 0 cinema, por exemplo, é

desde 0 início uma mistura fascinante de espetáculo, indústria, negócio, técnica, arte e inclusive magia. $\mathrm{O}$ cinema é imagem em movimento. A fotografia reflete a realidade e o cinema dá vida a essas imagens, as anima. 0 cinema cria no espectador uma ilusão de realidade, mas, na verdade, essa realidade está desfigurada pela técnica narrativa, pelos ângulos da câmera, pela forma com que se filma uma cena, pela montagem etc. (Feldman, 1984, p. 46)

Sabemos que a percepção da realidade muda segundo uma gama imensa de filtros e variáveis, desde 0 contexto cultural, a história pessoal e familiar, classe social, gênero, idade, disposições herdadas etc. Mas, como vimos acima, vai se formando no contexto da cultura midiática uma percepção da realidade altamente fragmentada, efêmera e impessoal, imersa no ambiente cultural da propaganda e do marketing. Os constructos simbólicos agenciados pelo sistema midiático-cultural e seu aparato tecnológico são pervasivos e atuam no longo prazo. Tomemos a percepção da guerra como exemplo. 0 que antes era distante no espaço e no tempo, com a transmissão ao vivo pela TV tornou-se próximo e até familiar, em virtude dos mapas e esquemas em 3D gerados por computador. Contudo, essa proximidade é exterior, não gera necessariamente identificação ou solidariedade. Participamos da guerra consumindo avidamente as imagens da guerra, ou seja: como espectadores de um filme que se desenrola diante de nós. A realidade cede à simulação, a guerra torna-se espetáculo: mísseis e "bombas inteligentes" são descritos em detalhes, 
em seguida mostra-se como funcionam, com casas e prédios indo pelos ares em explosões multicoloridas. A estética da morte pode inclusive fazer subir as ações na Bolsa de Nova York ${ }^{13}$ e, se mostra a dor das vítimas, essa dor quase não nos atinge mais.

Suponhamos que a técnica a serviço do mercado transforme a guerra em jogo interativo, e possa-se jogar a guerra em casa ou na escola. Os personagens e as paisagens do drama histórico, que custou a vida de milhares de pessoas, viram figurações fantasmáticas na tela do monitor. Os jogadores podem assumir ora a "personalidade" de um, ora a de outro contendor e mudar a seu gosto a configuração de personagens, arsenal, locais de luta. A experiência deslocaliza-se, perde aderência à realidade histórica para imergir no arbitrário da realidade virtual. No entanto, para um aficionado, as situações que "enfrenta" e as emoções que "vive" no jogo podem ser de uma realidade subjetiva muito mais intensa que a realidade objetiva do seu próprio cotidiano, no qual também morrem pessoas de verdade. Perante a dinâmica do hipertexto a própria realidade torna-se "sem graça" e "lenta". Pode ser que o jovem aficionado, como alguns soldados norte-americanos, busque na guerra ou em conflitos reais a chance de "reviver" emoções que experimentou em seus videogames. ${ }^{14}$

Casos extremos mostram que tais mudanças na percepção da realidade, sobretudo entre jovens de determinados segmentos sociais, estão avançadas. Nos Estados Unidos e na Europa têm acontecido assassinatos em escolas, praticados por adolescentes viciados em jogos violentos. No Brasil, os quatro jovens de classe alta que atearam fogo ao índio $\mathrm{G}$ aldino afirmaram que queriam fazer apenas uma brincadeira. Ainda mais extremo é o caso do comércio de fitas de vídeo que mostram imagens de tortura e morte de pessoas reais. Provavelmente entram na explicação de tais tragédias fatores de ordem familiar, componentes sociais, desvios psíquicos etc. $\mathrm{O}$ que a cultura midiática, especificamente, parece cultivar é um experimentalismo e um voyeurismo mórbidos, que não reconhecem fronteiras entre o real e a ficção. A sedução midiática - penso, sobretudo, no culto à violência em filmes e jogos - exacerba uma fantasia adolescente de provar experiênciaslimite, "curtir" emoções cada vez mais fortes; emoções estas que sua realidade cotidiana - previamente banalizada pela mesma mídia - não pode proporcionar.

A perda de sensibilidade e da habilidade para organizar valorativamente 0 real, o embotamento da capacidade para perceber a 
alteridade e 0 sofrimento humano, inclusive o próprio, são conseqüências que se podem prever nesta crônica de uma morte anunciada. Baudrillard (2001) chegou a falar de um verdadeiro "assassinato do real", de um desaparecimento do real em conseqüência justamente do excesso de realidade, de uma sobreexposição de realidade que dissolve todo limite, todo critério e referência. A dissolução crônica dos parâmetros de percepção contribui para o processo social de fabricação da insensibilidade.

Talvez por isso a "procura da 'realidade real' reapareça na arte contemporânea com um vigor inesperado" (Schøllhammer, 2002, p. 77). Em muitas escolas nota-se também um esforço pedagógico para fortalecer laços imediatos, favorecer contactos pessoais dos alunos com realidades de exclusão e sofrimento, encontros com pessoas de outras culturas e de outras etnias. Em tais iniciativas pode-se começar um diálogo com o diferente, praticar a sensibilidade para com a realidade do sofrimento, e contribuir para que pessoas atingidas pela marginalização recuperem narrativamente sua identidade e dignidade.

Ainda no contexto das mudanças na percepção da realidade introduzidas pelas novas tecnologias, só posso mencionar de forma rápida a realidade criada pelo cyberspace. ${ }^{15} \mathrm{O}$ mundo da simulação virtual, com suas virtudes e vertigens, tornou possível e atraente a total deslocalização e desmaterialização da experiência:

Los mundos virtuales equivalen a una verdadera revolución copernicana. Antes girábamos alrededor de las imágenes, ahora vamos a girar dentro de ellas (...). Como herramienta de escritura, la imagen de síntesis modifica nuestra relación con lo real, estructurándolo de otra manera. Como lugar virtual, establece lazos inéditos entre la concepción y la percepción, entre los fenômenos perceptibles y los modelos inteligibles. (Q uéau, 1995, p. 11 e 36)

Conforme Quéau, tudo o que se refere profundamente à imagem do homem, à sua presença perante os demais, tem necessariamente conseqüências psicológicas, filosóficas e morais. Certamente 0 virtual, como invenção humana que recria 0 humano e a própria realidade, também abrirá possibilidades novas e positivas em diversas áreas, inclusive nas práticas pedagógicas. Para Quéau o desafio será nos convencermos disto a tempo, de forma que não se permita que apenas a lógica dos negociantes e dos técnicos de computação decida acerca da utilização de nossa imagem e de nossa memória (1995, p. 95). ${ }^{16}$ 


\subsection{Mudanças na formação da identidade e dos sujeitos}

Parágrafos acima mencionei os processos de composição e recomposição permanente da identidade como fundamentais para a formação dos sujeitos. Os mecanismos de percepção e filtragem da realidade, conquanto dinâmicos, são essenciais para a constituição de uma identidade e para a própria subjetividade, essa noção do "eu interior", típica da civilização ocidental. É notável que um autor como Giddens identifique o surgimento de "novos mecanismos de auto-identidade que são constituídos pelas instituições da modernidade, mas que também a constituem" (Giddens, 2002, p. 9), e sequer mencione 0 sistema midiático-cultural como o mais importante conjunto dessas "instituições". Nas suas observações sobre a transformação da intimidade e sobre o eu - entendido como um projeto a ser organizado reflexivamente pelos sujeitos, enquanto constroem os próprios contextos institucionais em que existem - , Giddens não examina, ou não concebe, que tais transformações da intimidade, como a incerteza, a cultura do risco, a opção por estilos de vida, a construção e o controle do corpo, a vergonha, o narcisismo e, afinal, a falta de sentido pessoal - identificada por ele como um problema psíquico fundamental na modernidade tardia -, estejam em ligação "orgânica" com a cultura produzida e difundida pelo sistema midiático-cultural. Mais ainda: que tais rupturas e transformações, ainda que não totalmente planejadas ou intencionadas, têm sido funcionais e necessárias para que 0 "capitalismo simbólico" amplie seu leque de possibilidades de acumular mais-valia e se consolide subjetivamente na vida social. A atual superoferta de terapias é sintomática, pois os indivíduos correm 0 risco de soçobrar emocional e fisicamente sob o peso das pressões do sistema. Eles precisam "amarrar" sozinhos os fragmentos do eu, dilacerado por pressões, ameaças, incertezas e cobranças.

Para Giddens, o projeto reflexivo do eu "consiste em manter narrativas biográficas coerentes, embora continuamente revisadas". Esse processo acontece hoje num contexto de múltipla escolha, filtrada por sistemas abstratos, e num quadro de crise das instâncias tradicionais mediadoras da identidade. 0 problema justamente é que em tal contexto se torna difícil manter narrativas biográficas coerentes; para narrar é preciso ter lembranças, cultivar memórias, saber articular discursivamente processos de vida e luta em unidades de sentido. Uma questão pedagógica básica permanece: Q ue características assu- 
mem identidades e subjetividades constituídas num ambiente cultural cada vez mais dominado pelo sistema midiático-cultural? $\mathrm{Ou}$, dito de outra forma: Como contribuir para que os processos de formação da identidade e da sujeiticidade incluam existencialmente valores como liberdade, participação, autonomia? Não será fácil dar uma resposta satisfatória a estas questões. Já vimos, mesmo que de forma rápida, como a cultura midiática e as novas tecnologias incidem no processo de formação da identidade de crianças e adultos. Algumas tendências perigosas foram identificadas:

- O esvanescimento da percepção dos limites entre real e ficção, induzido pela simulação virtual, pode favorecer o desinteresse pelas realidades locais e concretas em benefício de uma fuga para a fantasia, que se "enche de realidade".

- A aceleração constante das experiências sensoriais na interface com os aparatos tecnológicos pode criar um estado de excitação contínua, que dificulta a concentração em outras situações de aprendizado.

- A superexposição à imagem, se não trabalhada, facilita a preguiça do pensamento, o desinteresse pela leitura e a conseqüente decadência da palavra e do pensamento argumentativo.

- A transitoriedade dos constructos simbólicos mediando as relações humanas pode gerar insegurança e certa angústia na criança, sobretudo quando ela não possui referenciais familiares mais sólidos.

- A perda da memória coletiva, substituída por lembranças alheias e de curto prazo, favorece a dessolidarização e 0 individualismo, incidindo sobre o processo de formação das identidades.

- A incessante pedagogia da propaganda busca formar nas crianças hábitos de consumo e lealdade a marcas, em detrimento da autonomia, do senso crítico e da lealdade a pessoas e causas concretas.

- A crescente expressão da intimidade por meio da mediação eletrônica pode desestimular a sociabilidade e o diálogo direto, que demandam habilidades próprias e maior envolvimento. 
- A oferta de gratificação instantânea, típica da cultura midiática, exerce uma pressão constante sobre a leitura e o aprendizado, que precisam adaptar-se; como tendência torna-se mais difícil para as crianças perceberem que algumas coisas demandam tempo para amadurecer e dar frutos.

- A superexposição às cenas de violência tende a banalizar a vida e a própria morte, contribuindo para um processo sociocultural de dessensibilização.

- A imersão na cultura midiática (com seus referenciais e aparatos tecnológicos) altera os quadros subjetivos de percepção da realidade e influi no processo de constituição das identidades e subjetividades.

- O espelhamento narcísico, pela imersão no mundo virtual, junto com a atomização da experiência nos quadros da cultura midiática vão influenciar o processo de constituição dos sujeitos (como capacidade para manter narrativas biográficas coerentes), ao excluir quaisquer referências comunitárias. 0 resultado, como indicam exemplos extremos, poderá ser a formação de subjetividades extremamente frágeis, imprevisíveis, egocêntricas e dessolidarizadas.

\section{Conclusão}

Somente é possível falar em "cultura midiática" quando se reconhece 0 fato de que a maioria absoluta da população é, desde sua mais tenra infância, socializada pelo sistema midiático-cultural. Isso aponta para a função pedagógica da mídia como a grande (des)educadora das massas e da infância. Um componente essencial ao sistema midiático-cultural e à própria cultura que ele produz é a publicidade e o marketing. Os produtos simbólicos altamente elaborados pela indústria do marketing e da publicidade acompanham-nos desde muito cedo, até o ponto de os julgarmos componentes "naturais" na nossa percepção da realidade, inclusive subjetiva. Seus ícones (Coca-Cola, McD onald's, Disney, Xuxa) ensinam as crianças a "ler" o mundo, a "identificar" e a "desejar" muito antes de elas serem alfabetizadas pela escola, às vezes antes mesmo de aprenderem a falar. As conseqüências desse processo de cooptação do imaginário infantil, mesmo se não totalmente investigado, já se mostram preocupantes. 
Felizmente as crianças não são usuários passivos da mídia. Sabemos que eles abordam a mídia a partir de suas histórias pessoais, das construções sociais cultivadas na família e na comunidade e que a psique humana possui um potencial vigoroso para lidar com tais influências (Arnaldo, 2002, p. 449). Além disso, no mesmo movimento de instauração de um sistema midiático-cultural e de uma cultura que lhe é funcional, a cultura midiática, os sujeitos podem repor novas formas de ação e reação, abrir brechas para a criatividade e criar novos espaços de resistência. Conforme Hinkelammert o sujeito em si ou a priori não existe, ele não é uma substância, uma entidade ou mesmo o indivíduo concreto, mas é uma "ausência que grita": 0 sujeito constitui-se enquanto se opõe e resiste à redução pretendida pelo sistema social dominante. Ser sujeito é responder ao chamado a tornar-se sujeito, que se revela no decurso de um processo, baseado na intersubjetividade, de busca do bem comum, contra as tendências autodestrutivas do sistema (2000, p. 77-78). O ser humano - como ator social, sempre finito e engajado em causas concretas, mas nunca esgotado pelas mediações históricas e sempre transcendente a seus papeis sociais - "(...) se afirma como sujeito gritando, se opondo a essa redução que torna sua vida insuportável" (Sung, 2000, p. 55).

Julgo, assim, que algumas questões urgentes e de fundo vão ocupar cada vez mais nosso esforço de pais, mães, educadores e agentes pedagógicos nos próximos anos:17 Como trabalhar pedagogicamente o impacto de uma cultura calcada na exteriorização mercadológica compulsiva? Se existe clareza de que não é possível deixar a formação das crianças nas mãos de marqueteiros e projetistas de videogame, como pensar a educação infantil em um contexto dominado pelo sistema midiático-cultural? Q ue estratégias pedagógicas e reservas de sentido podem ser acionadas para resistir produtivamente a este modo de ser orientado à exteriorização publicitária, ao espetáculo e ao descartável?

Recebido em maio de 2003 e aprovado em julho de 2003.

\section{Notas}

1. Segundo D ênis de Moraes, a invasão audiovisual no Brasil "pode ser medida pelo volume de filmes norte-americanos exibidos pelas TVs por assinatura. Em maio de 1998, a TVA, do Grupo Abril, exibiu 865 filmes... dos quais 650 produzidos nos EUA - o que repre- 
senta $75 \%$ do total. As películas européias somaram 153 (18\%)... Ao cinema brasileiro coube a ínfima cota de 21 filmes (2,5\%). Nenhum outro país latino-americano entrou na seleção". (1998, p. 70).

2. Prefiro o termo "midiatização" da cultura, para realçar o papel ativo da mídia no processo. "Midiação" ou "mediação" parecem-me termos indefinidos e/ ou ambíguos. O termo "mídia" já é estrangeirismo (pronúncia brasileira do inglês media), mas o equivalente português "meios" não se firmou. "Mídia" tornou-se hoje praticamente o termo técnico para se referir ao conjunto dos meios de comunicação social, inclusive Internet e jogos eletrônicos, e é utilizado aqui nesta acepção.

3. O conceito de indústria da cultura, criado por Adorno em 1944, na primeira versão da D ialética do esclarecimento, é um dos mais férteis, e debatidos, das ciências sociais. Estou fundamentalmente de acordo com a crítica adorniana da universalização do princípio da mercadoria, que toma posse do âmbito da cultura, de sua análise da indústria da cultura como estetização da realidade, e da fetichização dos produtos culturais. No entanto, não creio ser necessário assumir o caráter totalizante de sua crítica; acho difícil afirmar a universalidade da pseudocultura, ou que todos os produtos da indústria da cultura são totalmente estandardizados até o núcleo formal de sua constituição; creio ser necessário levar em conta as formas e condições de incidência específica dos produtos culturais e considerar que sua recepção pelo público gera, como todo processo social, também efeitos não planejados e conseqüências não controladas. Mas a discussão pró e contra continua: cf. Cohn, 1998; Esteves, 2001; Steinert, 1998; Thompson, 1998; Zuin, 1999; e o excelente estudo de Zamora, 2000.

4. Para alguns membros de movimentos sociais na Índia, a chamada globalização cultural serviu para enfraquecer o sistema de castas e, conseqüentemente, possibilitou alguma ascensão social para os párias (daliths) e mais direitos para as mulheres; cf. Menon, 2000, p. 24-28.

5. Woodward, 2000, p. 18; grifo meu.

6. “(...) a identidade marca o encontro de nosso passado com as relações sociais, culturais e econômicas nas quais vivemos agora... a identidade é a intersecção de nossas vidas cotidianas com as relações econômicas e políticas de subordinação e dominação" (Rutherford, 1990, p. 19-20, apud Woodward, 2000, p. 19).

7. "O bê-á-bá eletrônico", Folha de S. Paulo, TV Folha de 19/4/ 2003, p. 6.

8. Apenas um exemplo dessa colonização do imaginário infantil pelas marcas e a publicidade: pesquisa recente mostrou que Ronald $\mathrm{McD}$ onald, o palhaço-mascote da rede de lanchonetes McD onald's é identificado por $96 \%$ das crianças norte-americanas. A logomarca da rede é mais conhecida que a cruz cristã e já é o segundo símbolo mais conhecido do planeta, só perdendo para 0 dos jogos olímpicos; cf. Fontenelle, 2002, p. 28.

9. "As marcas são a nova religião", declarou nesta semana a Young \& Rubicam, uma das maiores agências de publicidade do mundo, ao publicar sua lista anual das marcas globais mais reconhecidas pelos consumidores. As marcas de sucesso, segundo ela, veicularam mais que um produto. Elas representaram um conjunto de crenças e as pessoas que as construíram agiram como os missionários que espalharam o cristianismo e o islamismo pelo mundo. "As marcas que estão tendo sucesso são aquelas vinculadas a crenças fortes e idéias originais", disse Young \& Rubicam. "São também as que possuem a paixão e o dinamismo para mudar o mundo e para converter as pessoas à sua maneira de pensar, por meio de comunicações de alto nível." "Brands, the last temptation of capitalism", publicado no Financial Times de 2/ 2/ 2001 e comentado pela Folha de S. Paulo de 4/ 3/ 2001, Caderno Mundo ("Publicitários dizem que marcas são nova religião"). 
10. "TV para bebês: apesar de não terem renda e de serem praticamente ignoradas pelo Ibope, crianças de até cinco anos são alvo da disputa entre os canais infantis", TV Folha, 13/4/ 2003.

11. Nos três primeiros meses de 2002 foram reportados três casos de ataques epilépticos fatais nos Estados Unidos, em conseqüência da exposição intensa das pessoas ao videogame Everquest; cf. "Mãe de jogador suicida processa Sony nos EuA", em www.uol.com.br/ folha/ informatica/ ult124u9665.shl (4/ 4/ 2002). Contudo, as vendas de videogames em 2001 superaram toda a arrecadação de Hollywood; cf. Folha Online, edição de 8/ 2/ 2002, "Venda de videogames bate recorde e supera Hollywood em 2001", em www.uol.com.br/ folha/ informatica/ ult124u9242.shl

12. "Jovem morre após passar 32 horas em frente do PC", em http:/ / www1.uol.com.Br/ folha/ informática/ ult12411358.shtml

13. A matéria "Bombas caem e bolsas sobem" de 0 Popular de 22/3/2003 sobre a guerra no Golfo dizia: "Mercado em festa. Indicadores financeiros alcançam recordes e investidores comemoram" (Mundo, p. 24).

14. Alguns soldados americanos diziam eufóricos na TV que a guerra no Iraque era mais emocionante e lhes dava mais "adrenalina" que qualquer jogo de videogame. Para Paul Virilio, não há mais separação entre 0 campo de batalha real e o virtual; conquistar o espaço virtual pela propaganda é tão importante quanto conquistar o território do país ocupado. Folha de S. Paulo, 6/ 4/ 2003, Caderno Mundo, A 24.

15. Muniz Sodré, em estudo recente e fecundo, incursionou pelos meandros técnicos e pelas implicações filosóficas do virtual como metáfora e espelhamento do humano (A ntropológica do espelho, 2002).

16. A grande metáfora do filme Matrix (1), ele mesmo um produto cultural altamente mercantilizado, é que a sociedade atual, mormente a norte-americana, já vive numa ambientação artificial, em tudo semelhante à imersão no hiper-real: numa alienação total (às vezes desejada) perante 0 desencanto e a falta de glamour da realidade, comandada pelo poder oculto de uma supermáquina, que ao mesmo tempo em que gera e alimenta, controla e vampiriza os humanos, inclusive os seus sonhos.

17. Felizmente algumas iniciativas promissoras têm surgido no âmbito da educação para a mídia: oNGS dos Estados Unidos e da Europa, especializadas na orientação dos pais; grupos de pressão para influenciar mudanças na legislação audiovisual e na programação das emissoras; e sobretudo o projeto internacional da UNESCO, dirigido explicitamente ao fomento e à discussão de programas de educação para a mídia (Carlsson \& Feilitzen, 2002). No Brasil um fruto desse projeto foi o Programa Educativo do Telespectador, voltado para a formação de professores (Arnaldo, 2002, p. 441).

\section{Referências bibliográficas}

\section{AD O RNO, T.W. G esammelte Schriften. Frankfurt a.M.: Suhrkamp, 1970. 20v.}
AD O RNO, T. W.; HO RKHEIMER, M. D ialek tik der A ufk lärung: philosophische Fragmente. Frankfurt: Fischer, 1982. (Ed. bras. D ialética do esclarecimento: fragmentos filosóficos. Rio de Janeiro: Zahar, 1985).


ALMEID A JR., A.R. Espelho eletrônico. Cadernos do IFA N, Bragança Paulista, n. 28, p. 49-72, 2001.

ARNALD O , C.A. Meios de comunicação: a favor ou contra a educação. In: Carlsson, U.; Von Feilitzen, C. (O rg.). A criança e a mídia: imagem, educação, participação. São Paulo: Cortez; Brasília, DF: UNESCO, 2002. p. 439-449.

ASSMANN, H. A igreja eletrônica e seu impacto na A mérica Latina: convite a um estudo. Petrópolis: Vozes, 1990.

BAUD RILLARD, J. Simulacres et simulation. Paris: Galilée, 1981.

BAUD RILLARD, J. Banalidade mortífera. Folha de S. Paulo, São Paulo, 10 jun. 2001. Caderno Mais!, p. 12.

BAUD RILLARD , J. A ilusão vital. Rio de Janeiro: Civilização Brasileira, 2001.

BERGER, P.; LUCKMANN, T. A construção social da realidade. Petrópolis: Vozes, 1978.

BOLAÑO, C.R.S. Economia política, globalização e comunicação. Revista N ovos Rumos, São Paulo, v. 11, n. 25, p. 15-23, 1996.

BUD DE, M. The (magic) kingdom of $\mathrm{G}$ od: christianity and global culture industries. Boulder: Westview, 1997.

BUDDE, M. Embracing pop culture: the Catholic Church in the world market. Cadernos do IFA N, Bragança Paulista, n. 28, p. 73-95, 2001.

CARLSSON, U.; VON FEILITZEN, C. (Org.). A criança e a mídia: imagem, educação, participação. São Paulo: Cortez; Brasília, DF: UNESCO, 2002.

CARVALHO, J.J. Religião, mídia e os predicamentos da convivência pluralista: uma análise do evangelismo transnacional norte-americano. In: Moreira, A. (O rg.). Sociedade global: cultura e religião. Petrópolis: Vozes, 1998. p. 79-112.

CASTELLS, M. Fluxos, redes e identidades: uma teoria crítica da sociedade internacional. In: CASTELls, $\mathrm{M}$. et al. $\mathrm{N}$ ovas perspectivas críticas em educação. Porto Alegre: Artes Médicas, 1996. p. 3-32. 
CASTELLS, M. La sociedad de la información: economia, sociedad y cultura. Madrid: Alianza, 1997-1998. v.1-2.

CHOMSKY, N.; HERMAN, E. Manufacturing consent. New York: Pantheon, 1988.

CHOMSKY, N. M edia control: the spectacular achievements of propaganda. N ew York: Seven Stories, 1997.

COHN, G. A atualidade do conceito de indústria cultural. In: Moreira, A. (O rg.). Sociedade global: cultura e religião. Petrópolis: Vozes, 1998. p. 11-26.

CURRAN, J.; GUREVITCH, M. (Ed.). Mass media and society. 2. ed. London; New York: Arnold, 1997.

ESTEVES, J.P. C ultura e industrialização: racionalidade e instrumentalismo. D isponível em: <http:/ / www.lab.demac.ufu.br/ espec/ pt/ estevespissarra-ind-cultural.html>. Acesso em: 30 nov. 2001.

FEATHERSTONE, M. Cultura global: nacionalismo, globalização e modernidade. Petrópolis: Vozes, 1994.

FEATHERSTONE, M. Cultura de consumo e pós-modernismo. São Paulo: Nobel, 1995.

FELD MAN, S. El cine: cara y ceca. Buenos Aires: La Flor, 1984.

FO NTENELLE, I.A. 0 nome da marca: McD onald's, fetichismo e cultura descartável. São Paulo: FAPESP; Boitempo, 2002.

GARCIA CANCLINI, N. Consumidores e cidadãos: conflitos multiculturais da globalização. 4. ed. Rio de Janeiro: UfRJ, 1999.

GERBNER, G. The electronic storyteller. [Northampton, MA]: Media Education Foundation, 1998. D isponivel em: <www.mediaed.org/ guides/ gerbner/ gssg1.html> Acesso em: nov. 2003.

GEYER, C.-F. E inführung in die Philosophie der Kultur. Darmstadt: Wiss. Buchgesellschaft, 1994.

GIDDENS, A. Modernidade e identidade. Rio de Janeiro: Zahar, 2002. 
GIRAUD, A. La dérégulation contre les nations. In: CASTEL, F. et al. L'ordre communicationnel: le nouvelles téchnologies de communication; enjeux et stratégies. Paris: La D ocumentation. Française, 1989.

HERMAN, E.S.; McCHESNEY, R.W. The global media: the new missionaries of corporate capitalism. London; Washington, DC: Cassel, 1997.

HINKELAMMERT, F.J. La vuelta del sujeto humano reprimido frente a la estratégia de globalización. Cadernos do IFA N, Bragança Paulista, n. 26, p. 67-80, 2000.

JANNEY, R.; ARNDT, H. Can a picture tell a thousand words?: interpreting sequential vs. holistic graphic messages. In: Nöтн, W. ( $\mathrm{Org}$.$) . 0$ rigins of semiosis: sign evolution in nature and culture. Berlin: Mouton de Gruyter, 1994. p. 439-453.

LEISS, W.; KLINE, S.; JHALLY, S. Social communication in advertising: persons, products \& images of well-being. 2. ed. London; New York: Routledge, 1997.

LIMA, D.M. 0 s demônios descem do N orte. Rio de Janeiro: Francisco Alves, 1987.

MARTÍN-BARBERO, J. D os meios às mediações: comunicação, cultura e hegemonia. Rio de Janeiro: UfrJ, 1997.

MATTELART, A. C omunicação-mundo: história das idéias e das estratégias. Petrópolis: Vozes, 1994.

MAtTelart, A.; MATtelart, M. Penser les médias. Paris: La D écouverte, 1986.

MENON, G. Eine hinduistische Antwort auf die Globalisierung. $\mathrm{G}$ rüne Schriftenreihe "B erichte-D ok umente-Kommentare", Bonn, n. 81, p. 24-28, 2000.

MONTGOMERY, K.C. Digital kids: the new on-line children's consumer culture. In: Singer, D.G.; Singer, J.L. (Ed.). H andbook of children and the media. Thousand O aks: Sage, 2000. p. 635-650.

MORAES, D. Planeta mídia: tendências da comunicação na era global. Campo Grande: Letra Livre, 1998. 
MORAES, D. (Org.). Por uma outra comunicação: mídia, mundialização cultural e poder. Rio de Janeiro; São Paulo: Record, 2003.

MOREIRA, A.; ZICMAN, R. (O rg.). M isticismo e novas religiões. 2. ed. Petrópolis: Vozes, 1994.

O'SULLIVAN, T.; DUTTON, B.; RAYNER, P. Studying the media. London: Arnold; Oxford University, 1998.

ORTIZ, R. M undialização e altura. 2. ed. São Paulo: Brasiliense, 1994.

PERNIO LA, M. E nigmas: o momento egípcio na sociedade e na arte. Rio de Janeiro: Bertrand, 1994.

QUÉAU, P. L o virtual: virtudes y vértigos. Barcelona: Paidós, 1995.

REIMUND, W. Ikonizität und emotionale Bedeutung bildlicher D arstellung. Frankfurt a.M.: Lang, 1993.

RUTHERFO RD, J. Identity: community, culture, difference. London: Lawrence and Wishart, 1990.

SAND BOTHE, M.; ZIMMERLI, W. (Ed.). Z eit-M edien-Wahrnehmung. D armstadt: Wissenschaftliche Buchgesellschaft, 1994.

SANTAELLA, L.; NÖTH, W. Imagem: cognição, semiótica, mídia. 2. ed. São Paulo: Iluminuras, 1999.

SCHILLER, H. Media, technology and the market: the interacting dynamic. In: Bender, G.; D RUCKER, T. (O rg.). C ulture on the brink: ideologies of technology. Seatle: Bay, 1994.

SCHØ LLHAMMER, K.E. À procura de um novo realismo: teses sobre a realidade em texto e imagem hoje. In: O LinTo, H.K.; Schøllhammer, K.E. (O rg.). L iteratura e mídia. São Paulo: Loyola; Puc Rio, 2002. p. 7690.

SO D RÉ, M. A ntropológica do espelho: uma teoria da comunicação linear e em rede. Petrópolis: Vozes, 2002.

STEINERT, H. Kulturindustrie. Münster: Westfälisches D ampfboot, 1998.

SUNG, J.M. Sujeito como transcendentalidade ao interior da vida real: um diálogo com o pensamento de Franz Hinkelammert. Cadernos do IFA N, Bragança Paulista, n. 26, p. 47-66, 2000. 
THO MPSO N, J.B. Ideologia e cultura moderna: teoria social crítica na era dos meios de comunicação de massa. Petrópolis: Vozes, 1995.

THOMPSON, J.B. A mídia e a modernidade: uma teoria social da mídia. Petrópolis: Vozes, 1998.

VIRILIO, P. Un paisaje de acontecimientos. Buenos Aires: Paidós, 1997. WEIDENMANN, B. Psychische Prozesse beim V erstehen von Bildern. Bern: Hans Huber, 1988.

WO O DWARD, K. Identidade e diferença: uma introdução teórica e conceitual. In: SiLva, T.T. (0 rg.). Identidade e diferença: a perspectiva dos estudos culturais. Petrópolis: Vozes, 2000.

ZAMORA, J.A. Teoria crítica da indústria da cultura. Cadernos do IFA N, Bragança Paulista, n. 26, 2000.

ZUIN, A.A.S. Indústria cultural e educação: 0 novo canto da sereia. Campinas: Autores Associados, 1999. 